\title{
Juvenile Punishment System in View of the Need for Education and Reintegration
}

Jola Bode

Assoc. Prof., University of Tirana, Faculty of Law

\section{Abstract}

Due to age and development stage, juveniles enjoy a special status in relation to adult persons. The status as a juvenile in the criminal field raises the request for treatment in accordance with the physical-psychic characteristics of the juvenile and his educational needs. The punishment system is an important component of the criminal justice system for juveniles. As such, it must respond to requests for a special treatment consistent with the personality of juveniles and individual education needs. This system should be oriented towards the goal of education and rehabilitation of the juvenile. In accordance with the international standards of juvenile justice and contemporary legislation, the Criminal Code of the Republic of Albania (CC) has sanctioned a number of rules that allow for special treatment for juveniles in the area of the punishment system. Despite the positive aspects, the provisions of the Code were insufficient in view of the requirements of international standards and the need for education and reintegration. The legal reform which also included the criminal justice system for juveniles brought a number of changes in the area of juvenile punishment system too. With the entry into force of the Juvenile Criminal Code (JCC) it was possible to establish a special and autonomous system of penalties applicable to juvenile offenders. The implementation of this system serves a friendly juvenile justice aimed at avoiding the negative effects of imprisonment and tends towards social rehabilitation and reintegration. This study discusses the novelties brought by JCC in terms of the meaning, classification and determination of juvenile sentence system and it will be reflected in relation to the challenges of the effective implementation of the provisions relating to the punishment system. Conclusions will also be drawn regarding the compliance of this system with the request for special treatment of juvenile perpetrators and the need for integration and reintegration.

Keywords: Punishment system, Juvenile Criminal Code, Punishment classification, Non-custodial sentence, Freedom restriction.

\section{Introduction}


For juvenile offenders the punishment must be an instrument of reintegration and resocialization policies. Today it is admitted that if the treatment of juveniles shall be made in the shadow of criminal law, it will remain under the influence of repressive and retributive orientation. ${ }^{1}$

Therefore, the punishment system should aim at promoting educational measures and alternatives to imprisonment in order to avoid the negative effects of imprisonment and to ensure the process of integration and education in the most efficient way. In the enforcement of penalties, consideration should be given to the need for education and the highest interest of the minor. This purpose also determines the types of punishments applicable, where, first and foremost, priority should be given to educational measures, and in general, to non-institutional measures. The custodial sentence shall be applied in exceptional cases and only for serious offenses. These principles also reflect the requirements of international criminal justice standards for juveniles. The principle sanctioned in Article 40 of the UN Convention "On the Rights of the Child" regarding the way children in conflict with the law are treated, is of particular importance in the determination of penalties, whose implementation should take into account the age of the child, the educational needs and the integration process ${ }^{2}$.

As part of the criminal justice system, the juvenile justice system has also been in a dynamic process of continuous change. Until before the adoption of JCC, the main reference point was the CC that entered into force with Law No. 7895, dated 27.01.1995, which despite all the positive changes, did not fully reflect the requirements of international standards for the treatment of juveniles. The legal reform in the justice system enabled a comprehensive reform of the criminal justice system for juveniles.

The adoption of Law no. 37/2007 "Juvenile Criminal Code", which entered into force on 1 January 2018, was the product of this reform. The JCC has brought a number of progressive changes to the juvenile justice system in line with international standards and the need for special treatment. Even after the entry into force of JCC, which already provides for a special legal framework for juveniles, a good part of the CC's provisions in this area still remain in force.

In the context of legal treatment, aspects related to juvenile punishment system are provided for both in the $\mathrm{CC}$ and in the JCC.

\section{Special rules in the area of juvenile punishment system in the Criminal Code}

According to the doctrine: "A criminal punishment in the criminal law of the Republic of Albania includes the coercive measure, which is enforced by the state through courts, in accordance with the law, against guilty persons who have committed a criminal

\footnotetext{
${ }^{1}$ Kambovski.V, (2006), Criminal law, general part, Print ISM, Skopje, p. 1085.

2 Ibid, Article 40/1.
} 
offense." 1 . The Criminal Code does not have a separate chapter reflecting aspects of the juvenile punishment system. Problems related to the treatment of juveniles are spread in various chapters of this code. Although there is no special chapter on juvenile punishment, CC, in line with international standards, provides for special rules in the juvenile punishment system, which aim at a favorable treatment for this category.

According to Article 51, juveniles who at the time of committing the criminal offense have not reached the age of 18 , the custodial sentence cannot be longer than half the sentence provided by the law for the criminal offense committed, so the juvenile cannot be punished more than half of the maximum and minimum, provided for by the relevant provision for the criminal offense committed. Regarding the imprisonment, Article 33 has stipulated the principle of serving the sentence in separate places from adults.

In accordance with the principle that the measure of imprisonment is the last measure that can be imposed, the CC in Article 52 has provided for the possibility of excluding the juvenile from the punishment. The possibility of excluding a juvenile from punishment is one of the most important aspects in the juvenile punishment process. According to the provision ${ }^{2}$, the exemption of the juvenile from the punishment is not an obligation for the court, but it is left to the court to assess the criteria for exempting the juvenile from the punishment. The discretionary nature of this provision as well as the lack of re-education institutions where the juvenile exempted from punishment can be placed, has led to inability to implement it. This issue has not been resolved even with the entry into force of the JCC, which does not provide for the exemption of the juvenile from the punishment.

A very important aspect of special treatment is the implementation of educational with minors. The $\mathrm{CC}$ has provided only one educational measure, that of placement in an educational institution and its mode of implementation ${ }^{3}$. The measure of placement in an educational institution is insufficient, has no implementation in practice and is in conflict with international standards that require the implementation of measures that do not isolate the child from the social environment. Regarding their sanctioning in the CC, scholars believe that the current criminal legislation has made a step back compared to the previous criminal legislation ${ }^{4}$.

\footnotetext{
${ }^{1}$ Prof. Dr. Elezi.I, Prof. Dr. Kacupi.S, Prof. As. Dr. Haxhia.M, (2009), Comentary of Criminal Code , West Print, Tirana, p. 197.

${ }^{2}$ According to Article 52 of the Criminal Code:

"The court, based on the low risk of a criminal offense, from the concrete circumstances of its commission, from the previous behavior of the juvenile, may exempt him/her from the punishment. In this case, the court may decide to send the juvenile to an educational institution".

3 The court may decide to send the juvenile to an educational institution when deciding to exempt him from the punishment as well as in cases where the minor has not reached the age of criminal responsibility.

${ }^{4}$ Hysi.V, (2006), Penologjia, PEGI,Tirana, p. 179.
} 
An appropriate way to enable special treatment for juveniles in accordance with educational needs is to apply alternatives to imprisonment. The CC suffered significant changes in the area of alternatives to imprisonment under Law No. 10023, dated 27.11.2008, for some additions and amendments to Law no. 7895, dated 27.01.1995, "Criminal Code of the Republic of Albania". This law, through additions and amendments, improved the content of the existing provisions and enriched the CC with new provisions including other forms of alternatives to imprisonment, such as semi-liberty or home stay, containing more favorable conditions for their implementation against minors.

Although their implementation has a general character, that is to say, they can be applied to both adults and juveniles, the changes made have had positive effects on the enforcement practice for juvenile offenders. The content of alternatives to imprisonment also enables a decision that is conditioned not only by the circumstances and importance of the offense, but also by the individual circumstances of the juvenile offender. This adjustment is reflected both in the existing alternatives and in the new alternatives that have been added to the CC.

More specifically, Article 59, which provides for the suspension of the execution of the sentence of imprisonment and the probation, although with a general regulation, is also used in cases referring to juveniles. With the changes that this article underwent with law 10023 dated 27.11. 2008, on some additions and amendments to Law no. 7895 dated 27.01.1995, "Criminal Code of the Republic of Albania", the circumstances upon which the court may place the convicted on probation have been added. These circumstances are now not only related to the offense but also to the personal qualities, age, health, family, social and professional conditions of the convicted person.

Semi-liberty as a new alternative sanctioned in article 58 of the amended CC, with its content, enables its implementation to juveniles too. The causes for which this option can be applied enable the application to juveniles particularly in cases related to the needs for their education, qualification or vocational training.

A new alternative, added with the changes made to the CC, is the home stay. Referring to the content of the provision 1, in accordance with international standards 2 this alternative measure brings an innovation to the CC, enabling favored treatment for young people up to 21 years of age.

At the same time, the establishment of the Probation Service as a body that, in the context of competencies, also oversees the execution of alternative sentences, has

\footnotetext{
${ }^{1}$ Home stay can also be applied to young people under the age of 21 with documented needs related to health, study, work, or family responsibilities.

2 Rule 3.3 of the Beijing Rules requires the extension of the principles reflected in these rules to young people who violate the law.
} 
made it possible to increase the degree of implementation in practice of these alternative sentences.

Although special remedies for juveniles have been provided for in the CC, these provisions are insufficient and are still far from meeting international standards for the establishment of a system of punishment serving the juvenile education and reintegration. The need for a reform of the criminal justice system for juveniles in general and the legal framework in particular led to the adoption of the JCC.

\section{Novelties and developments in JCC}

The entry into force of the JCC enabled a differentiated treatment in accordance with the highest interest of the juvenile. In a general analysis, the JCC presents a whole set of very distinct features in the punishment system area.

Unlike the CC, which provided only certain special arrangements for juveniles, the JCC provides for, for the first time, an autonomous punishment system applicable to juvenile offenders.

The sanctioning of a special system of juvenile sentence is in line with the purpose of the re-socialization, reintegration and rehabilitation of the juvenile, which is explicitly stipulated in the Code bringing a novelty in this regard ${ }^{1}$.

Sentences provided for in this Code may be imposed only by specialized juvenile justice courts.

All structures involved in the implementation and monitoring of juvenile sentences should be specialized.

Another novelty of the JCC is the sanctioning of the general principles of punishment 2. Taking into consideration the way they are regulated by the Code, these principles are not purely declarative, but impose obligations to be taken into account by the court in the case of punishment. Consequently, we think that the juvenile judge in every case of sentence should consider the obligations that lay down these principles of the same importance as the rules laid down in Article 47 of the $\mathrm{CC}$ for determination of the sentence.

In the spirit of the international standards of juvenile justice, the code has sanctioned some important principles that the court should consider in the decision-making process:

The custodial sentence for juveniles is the last possible resort that is considered only if the avoidance measures provided for in the code are unsuitable;

\footnotetext{
${ }^{1}$ Article 93 of the JCC stipulates that the purpose of the juvenile punishment is:"Re-socialization , reintegration, rehabilitation and prevention of re-committing the offense or commission of another criminal offense, offering the juvenile care, assistance and supervision".

2 JCC, Article 94.
} 
When making a decision, the court should consider the best interest of the minor as well as the individual assessment report;

The sanctioning of this remedy aims at a decision-making by the court in accordance with individual circumstances and educational needs. Now any decision on the juvenile should be based on the elements of the individual assessment report as well as the fact that in making the decision the court is obliged to consider not only aspects related to the circumstances and the danger of the offense but also to the age, individual circumstances and special needs of the juvenile ${ }^{1}$.

The court shall also:

- Enable decision-making that promotes juvenile reintegration and their involvement in a more constructive role in society;

- Give the most appropriate sentence to rectify the juvenile's behavior.

- JCC brings novelties also with regard to types of juvenile punishments, enabling a new division of punishment types into two categories:

- Non-custodial sentences; and custodial sentences.

- For the first time, JCC provides for new penalties applicable to minors such as the restriction of liberty, juvenile imprisonment etc.

- The JCC sanctions an autonomous system of juvenile sentence classification in main sentences and additional sentences distinct from that of adults.

The Code foresees alternative measures of avoidance as a way to avoid criminal prosecution or punishment for juveniles and to enable their social integration. Considering this category, it can be concluded that juveniles can be subject to:

- Alternative avoidance measures (which mainly have the purpose of avoiding prosecution);

- Sentences.

As the alternative measures of avoidance have a number of distinctive features from the penalties relating to the procedural stage of enforcement, the competent bodies for their enforcement as well as the legal consequences, only penalties that may apply to juvenile offenders will be discussed below.

\section{Types of sentences applicable to juveniles}

The punishment system provided for in the JCC applies only to juvenile offenders who have reached the age of criminal responsibility, i.e. for juveniles of the age of 14 who have committed crimes and 16 years of age who have committed criminal offenses. ${ }^{2}$ The JCC does not contain provisions for juvenile offenders under the age of criminal responsibility, referring in such cases to provisions envisaging more specific laws 3 .

\footnotetext{
1 Ibid, Article 94/3(b).

2 Ibid, Article 3/11.

3 Ibid, Article 4/2.
} 
According to the JCC, juveniles can be subject to the following sentences 1 :

Non-custodial and custodial sentences.

2. Non-custodial sentences include:

a) restriction of liberty;

b) home stay;

c) fine;

d) doing work of public interest;

dh) the ban on carrying out an activity;

e) fulfillment of certain obligations.

Juvenile sentences are classified into major and complementary penalties 2 .

Incarceration, restriction of liberty and fines are the major sentences, while all other sentences are complementary ones.Only one major sentence can be given to the juvenile. The major sentence can be given together with no more than one complementary sentence.

Together with the sentence, one or more of the measures provided for in Chapter VII of the Code may be given. In an analysis of the provisions of the code, we can identify some characteristics for each of the types of sentences.

Custodial sentence: In accordance with international standards 3 , the custodial sentence of juveniles, as a form of deprivation of liberty, should be given as a last resort and when no other punishment alternative is appropriate. Based on this principle, the enforcement of the custodial sentence is conditioned by some criteria that the court must take into account when giving it to juveniles.

Unlike the provisions of the $\mathrm{CC}$, the JCC brings a number of changes regarding the length of time and the criteria for the enforcement of juvenile imprisonment.

With regard to duration, Article 97/2 of the JCC stipulates that the custodial sentence cannot be more than half of the punishment provided for the offense committed 4, but not more than 12 years. When enforcing a sentence of imprisonment, the judge is obliged to deduct half of the sentence provided for in the provision for the criminal offense, but in any case the court cannot give a sentence of more than 12 years. This

\footnotetext{
1 Ibid, Article 95.

2 Ibid, Article 96.

${ }^{3}$ This principle is enshrined in a number of international legal acts such as: Rule 1 of the United Nations Rules "On the Protection of Juveniles Deprived of Liberty", Article 37/b of the UN Convention "On the Rights of the Child", Article 46 of the United Nations Directives "On Prevention of juvenile delinquency" (Riyadh Directives) Rule 19.1 of the United Nations Standard Minimum Rules "On Juvenile justice administration" (Beijing Rules) etc.

${ }^{4} \mathrm{CC}$, Article 51.
} 
rule is mandatory for the court and does not provide the judge with discretion to assess case by case. In the legal doctrine there is an opinion that the sanctioning of such regulations regarding the duration of juvenile imprisonment should extend to the institutes of prescription and rehabilitation, considering that the prescription deadlines refers to the sentence measures provided for by the special provision and not halving them 1 .

As regards the conditions of enforcement, juvenile imprisonment may only be applied in cases where a criminal offense has been committed for which the minimum sentence is seven years and when this sentence is necessary due to the nature, social high risk of the criminal offense and the degree of guilt. This criterion is also imperative.

When deciding on incarceration, the court takes into consideration all the circumstances related to the maturity of the juvenile and the time it takes for his/her professional education and training.

Depending on the degree of guilt, the court may grant a shorter sentence if it is considered sufficient to achieve its purpose 2 .

Regarding the manner of serving the sentence of imprisonment, according to Article $33 / 3$ of the CC, juveniles serve the sentence in separate places from adults.

Restriction of liberty. It means the placement of a minor in a particular institution/center under supervision without being isolated from society and the community, with the purpose of education and rehabilitation through special programs ${ }^{3}$. The restriction of liberty is realized in institutions with a low level of security, with a small number of minors enabling their individual treatment. These institutions should be geographically distributed throughout the country and be integrated into the social, economic and cultural environment of the community. With regard to duration, the restriction of the juvenile's freedom cannot be more than three years. The practical implementation of this measure is closely related to the creation of the necessary infrastructure, the establishment of special centers and institutions as well as human capacities with specialized and trained personnel in the field of juvenile justice. Currently, the establishment of these centers is still ongoing and is not completed.

Fine. A fine can be imposed by the court for both the persons who commit a crime and those who commit an offense. Measures and provisions regarding the imposition of a fine are stipulated in the $\mathrm{CC}$, where no special provisions for the determination of the fine for juveniles are provided for. Considering this deficiency, the JCC for the first

${ }^{1}$ Hoxha. D, Kacupi. S, Haxhia. M, (2018), Criminal Law, General Part, Jozef Publications, Durrës, p. 617.

2 JCC, Article 97/3.

3 JCC, Article 98/1. 
time foresees special provisions in this regard. The Code provides for two important criteria that the court should consider when enforcing a fine for juveniles:

This penalty can be applied to a juvenile only if he/she has monetary income from a lawful source 1;

Its amount cannot exceed half the fine that can be imposed on an adult under the same conditions pursuant to the Criminal Code.

By sanctioning these criteria, the shortcomings of the $\mathrm{CC}$ are remedied regarding the fine. The lack of specific criteria made it almost impossible to apply to juvenile offenders. This is also evidenced by the case law where Article 34 of the CC that provided for the fine penalty has barely been applied to juveniles..

\section{The ban on carrying out an activity}

2. It means the ban to carry out a certain activity for a period of time from one to three years. This kind of sentence is imposed when the court finds it appropriate to rehabilitate the juvenile and prevent the commission of other offenses by him/her. This sentence may be applied until the juvenile has reached the age of 18 .

Also, in the wording of this provision, there is an uncertainty as to the type of activities that a juvenile who has not reached the age of 18 can be prevented from performing. The possibility that this category carries out professional activity or activity related to functions or duties due to age is almost excluded. Therefore, we also think that for this kind of punishment the shortcomings in the wording of the provision can create implementation problems in practice.

\section{Doing work of public interest}

3. This punishment consists of placing a juvenile to carry out a job in public interest from 40 to 300 hours with a duration of no more than four hours a day. Carrying out work in the public interest can be assigned as a complementary punishment (the court implements it together with a major punishment) or as an alternative punishment. As a complementary punishment it may be imposed for a shorter time than the minimum of the foreseen hours. In cases where work in the public interest replaces the custodial sentence it may be longer in time. Work in the public interest is implemented in such a way as not to impede the education process and may be accompanied by the obligation to pursue a professional course.

Assigning work in the public interest as a complementary punishment and as an alternative punishment can create confusion in the practice of court enforcement.

\footnotetext{
1 The term "lawful source" is unspecified and may create different practices in the application of this provision. The same concern was raised by Albanian Helsinky Comity in the legal review that was made by this body to JJC. For more information, see AHC's legal review on the draft law" Juvenile Justice Code", (https://www.ahc.org.al/kodi-i-drejtesise-per-te-mitur).

2 JCC, Article 100.

3 Ibid, Article 101.
} 
Enforcement as an alternative punishment is very helpful to juvenile offenders considering the need for education and social reintegration for this category. With regard to enforcement as a complementary punishment, we consider it inappropriate to assign together with one of the major punishments, imprisonment, restriction of liberty or fine. We express the opinion that the practice of enforcement to juveniles, work in the public interest as a complementary punishment can be considered an appropriate punishment only if it is to be assigned as a separate punishment, unaccompanied by the major punishment. The JCC does not expressly provide for the possibility that the court may be suffice with the complementary punishment. Nevertheless, even in the case of punishment of juveniles, the regulations of the CC are applicable, which in certain cases enables the assignment of complementary punishment alone. ${ }^{1}$.

Fulfillment of certain obligations ${ }^{2}$. This punishment consists in ordering a minor to fulfill one or more of his obligations, such as: attending compulsory education or an educational program, attending a vocational training program, meeting the obligations arising from the employment relationship, repair of civil damage caused, attendance of a psychological or medical rehabilitation program, non-attendance of certain places, non-accompaniment with certain persons, etc. The list of obligations provided for in this Article is not exhaustive since the court may also impose other obligations provided for in Article 60 of the CC or obligations which it deems to be in the best interest of the minor. Fulfilling the obligations by the juvenile may be one of the most effective means with which the court, through the punishment system, enables its education in relation to the individual circumstances and the needs of the juvenile. Measures such as the repair of damage or the attendance of education, rehabilitation programs etc. serve the need for awareness of the minor for the offense committed, education and training, or narcotic substances in order to become a worthy member of the society. For this reason, courts should be encouraged to apply such measures.

Home stay 3 . This penalty means the juvenile's obligation not to leave, for a specified period, his permanent or temporary residence or a certain place where he is staying or being temporarily cured. This penalty may be applied in cases of commission of criminal offenses for which a punishment of up to five years of imprisonment is foreseen. As far as the duration is concerned, home stay is granted for a period of six months to one year. It applies in such a way that it does not hinder the educational

\footnotetext{
${ }^{1}$ Referring to Article 30/2 of the CC:

"The court in special cases, when the granting of the major sentences is deemed inappropriate and when the law provides for a sentence of imprisonment up to 3 years, or other lighter sentences for the offense, it can only be sufficed with imposing a complementary sentence".

2 Ibid, Article 102.

3 JCC, Article 103.
} 
process or the employment of a juvenile. Home stay can also be supervised electronically.

After analyzing the classification and types of penalties the following question may naturally arise: Does JCC provide for alternatives to imprisonment?

Although the JCC does not provide for a special system of alternatives, the Code provides for special provisions for the implementation of several alternatives to juveniles such as the suspension of the execution of the custodial sentence ${ }^{1}$ or reduction of the sentence below the minimum provided for by law. A Very positive development in this regard is the sanctioning of the most favorable terms of serving the sentence for obtaining parole as provided for in Article 129 of this Code. With the exception of some more favorable conditions for the application of alternative punishments, the JCC does not bring any novelty regarding the provision of new juvenile imprisonment alternatives.

We believe that the JCC should provide for a more complete provision of juvenile sentence alternatives without the need for reference to the relevant provisions of the CC.

Likewise, the JCC should have provided for a special system of alternatives applicable to juveniles. A wider space in this direction should have also been devoted to sanctioning the mechanisms that enable informal resolution of issues involving juvenile offenders, including mediation and restorative justice.

\section{Conclusions and recommendations}

The approval of the JCC paved the way for the creation of a special legal framework for juvenile justice in line with international standards and contemporary norms. The punishment system is a very important component of this framework. The JCC brings a number of novelties in the area of the punishment system by enabling an autonomous system applicable only to juvenile subjects and an approach towards a friendly justice that is aimed at the education, rehabilitation and reintegration of the juvenile. In compliance with international standards, the JCC has sanctioned for juvenile offenders a range of guarantees in the area of the system of punishments and punishment assignment. The sanctioning in the JCC of the purpose and types of juvenile punishment represents a positive development in terms of meeting international standards for the treatment of juveniles.

\footnotetext{
1 Two conditions must be met for the implementation of this alternative to juveniles:

- The court should impose a sentence of up to 5 years; and

- The juvenile shall not be convicted before for deliberately committing a criminal offense.
}

The amendment to Article 59 of the CC sanctioning this alternative for adults is related to the fact that Article 104 of the JCC does not provide for other conditions related to the person's risk or personal circumstances. See JJC, Article 104. 
Despite the positive changes, by referring to the provisions of the Code, some conclusions can be drawn and some recommendations can be given on the concrete needs for intervention as follows:

Some of the provisions of the JCC that provide for the classification and types of juvenile punishments should be clarified and improved in terms of content to enable the implementation in practice but also coherence with the provisions of the CC.

Provisions on juvenile education measures had to be sanctioned in the JCC. One of the shortcomings of the JCC is the lack of provisions in this regard. The only educational measure provided for in the $\mathrm{CC}$, that of placement in a re-education institution, is a measure that implies separation from the social environment. Moreover, in the absence of institutional infrastructure, this measure cannot be implemented. The lack of a variety of educational measures does not comply with the requirements of international legal acts to give priority to these measures against juvenile punishment.

The JCC should have provided for a contemporary system of alternative punishments applicable only to juveniles. The alternatives to imprisonment provided for in the CC are applied by case to both adults and juveniles, without distinction based on juvenile status. Despite the positive changes that the CC underwent in this area, there is still no alternative system of punishments applicable to juveniles.

Even the entry into force of the JCC has not resolved the issue of the treatment of juveniles who, because of their age, are exempted from criminal liability. Although there are no penalties for this category, the JCC should have provided for measures to be taken in order to enable rehabilitation and reintegration into the society.

In accordance with the advanced Western legislation 1, specific regulations for the treatment of age groups over the age of 18 should have been sanctioned in the JCC.

Changes to the JCC should also correspond to the necessary basis of secondary legislation, as well as the institutional infrastructure as a condition for establishing a system that takes into consideration the best interest of the juvenile and his/her educational needs. A number of measures must be taken to enable the application of the juvenile justice system. Interventions in this direction should consist of:

Creation of the necessary institutional infrastructure, establishment of the necessary structures provided for in the Code, special centers and institutions for the enforcement of sentences.

Adjustment of the necessary human resources to enforce obligations arising from the entry into force of this code.

\footnotetext{
1 The French, German, etc. criminal law provide for a differentiated treatment for persons of the age group 18-21, who constitute a special category for the purpose of determining the sentence and the effect of serving the imprisonment sentence.
} 
Training and specialization of competent bodies involved in the process of their implementation and supervision.

Judging juveniles by judges trained and specialized in juvenile justice and with extensive knowledge not only of domestic law but also of international acts of juvenile justice.

Improvement of the child services system as a system of victim-offender mediation, custody service, community services as well as all services that enable the social integration of juveniles against whom alternatives to imprisonment will be applied.

Adjustment of the Probation Service staff to juvenile justice specialists 1.

\section{Bibliography}

[1] Albanian Helsinky Comity, (2005), Juvenile system justice in Albania, PEGI, Tirana, 2005.

[2] Albanian Helsinky Comity, (2007), Respecting the right of defendants in criminal proces, PEGI, Tirana, 2007.

[3] Albanian Helsinky Comity, (2018), Legal review of the draft law "Juvenile Criminal Code in the Republic of Albania", (https://www.ahc.org.al/kodi-idrejtesise-per-te-mitur).

[4] Constitution of the Republic of Albania (1998).

[5] Hysi. V, (2006), Penalogia, PEGI, Tirana.

[6] Kambovski.V, (2006), Criminal law, general part, Print ISM, Skopje.

[7] Prof. Dr.I. Elezi, Prof. Dr. S. Kacupi, Prof. As. Dr. M Haxhia, (2009), Comentary of Criminal Code, West Print, Tirana.

[8] Prof. Dr.D. Hoxha, Prof. Dr. S. Kaçupi, Prof. Dr. M. Haxhia, (2018), Criminal law, general part, Botimet Jozef, Durrës.

[9] Law no. 37/2017 Juvenile Criminal Code.

[10] Law no. 7895 dated, 27.01. 1995, "Criminal Code of the Republic of Albania", as amended.

[11] Law no. 10023 dated 27.11.2008, on some additions and amendments to law no. 7895 dated, 27.01.1995, "Criminal Code of the Republic of Albania".

[12] Law no. 8328, dated 16.4.1998, "On the execution of criminal decisons".

[13] Law no.10024, dated 27.11.2008, on some changes and additions to law no. 8331, dated 21.4.1998 "On the execution of criminal decisons".

\footnotetext{
1 The accompanying report of the JJC expressly includes the request for increasing the number of Probation Service staff to deal with the supervision of alternative measures of avoidance as well as the specialization of employees in the area of juvenile justice. For more information see the Report on the draft law "Juvenile Justice Code in the Republic of Albania", p. 28,

(http://www.academia.edu/32116327/RELACION_KODI_I_DREJTESISE_PER_TE_MITURIT).
} 
[14] Report on draft law "Juvenile Criminal Code in the Republic of Albania", (2018), (http://www.academia.edu/32116327/RELACION_KODI_I_DREJTESISE_PE R_TE_MITURI).

[15] Resolution $1997 / 730$ of the economic and social council "On the administration of juvenile justice".

[16] Guidelines for action on children in the criminal justice system, annex to the Resolution 1997/730 of the economic and social council "On the administration of juvenile justice".

[17] Recommendation (87)20, "On the social response to juvenile delinquency".

[18] Recommendation (2003)20 "On new methods of treating juvenile crime and the role of juvenile justice". ${ }^{1}$

[19] Juvenile justice strategy 2017-20120, June 2017.

[20] UN Convention "On the rights of the child".

[21] United Nations Standard Minimum Rules "On the administration of juvenile justice". 